\section{WILL YOU REMEMBER THE BDA BENEVOLENT FUND?}

Founded in 1882, the BDA Benevolent Fund continues to help dentists and their families in times of crisis.

The Fund relies on your generous donations, and regardless of the size, legacy gifts remain essential in helping the Fund to continue its vital work. This is a great way of giving something back to the profession and your bequest will be exempt from Inheritance Tax.

If you would like to leave a legacy gift to the BDA Benevolent Fund, please contact your solicitor. Research shows that while many people may want to leave a gift in their will, only 7\% actually do.' By leaving a donation in your will, you could help someone in need put food on the table, pay for clothes or living expenses and enhance their quality of life.

Please help future dentists and their families in times of crisis by remembering the BDA Benevolent Fund in your will. The Fund relies on your help to continue its work, so for more information please contact us at administrator@dentistshelp.org or visit www.bdabenevolentfund.org.uk.

If you are in need of help yourself, please contact us now: all enquiries are considered in confidence.

1. Remember A Charity. Why leave a gift in your will. Available online at http://www.rememberacharity.org.uk/why-leave-a-gift-in-your-will/ [accessed 26 March 2015].

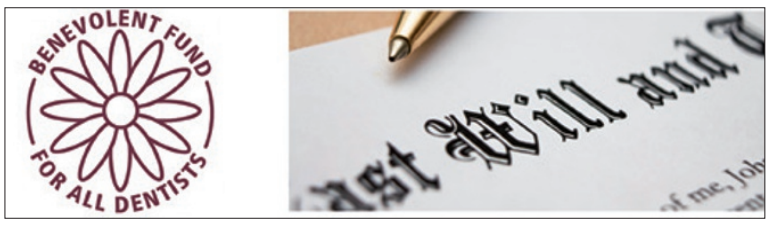

\section{GET TO THE BOTTOM OF PRACTICE VALUE}

Are you concerned with how to achieve the optimum value for your practice? The experts at Christie + Co can help.

Christie + Co understand the complexities of valuing, advising and brokering sales in highly specialised arenas, such as dentistry, and are ready and willing to assist you in realising the best value for your practice.

The dental sector is unique in its approach to value and in a market that experiences constant and rapid change; there are numerous factors that can affect valuation. A RICS-registered valuer, such as Christie + Co, can provide a true market value assessment for your practice and is able help you navigate the com- mon pitfalls of practice valuation.

The award winning team brings a wealth of experience, and with specialists located across the UK, Christie + Co works closely with its clients to ensure they receive the best opportunities and market insights. If you are looking to sell your practice and are unsure of how to proceed, contact Christie + Co today for expert and experienced advice.

To discuss how Christie + Co might help you achieve your future plans please contact Simon Hughes on 02072270749.

\section{RESTORE IMPLANTS WITH CONFIDENCE}

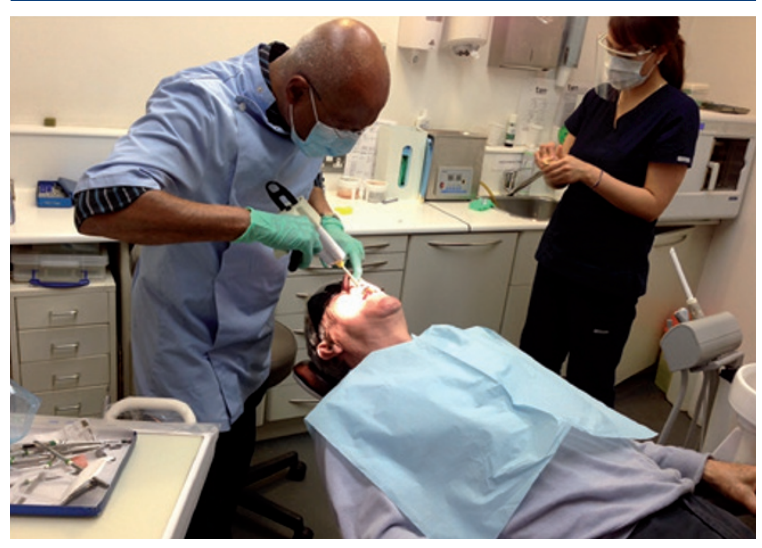

Brand new course dates have been released for the popular and in-depth Implant Restorative Course run by the experts at Ten Dental.

Learn from top-class implant mentors and trainers - Dr Martin Wanendeya and Dr Nik Sisodia. With many years of experience, they can guide you through the complete process offering you the insight and knowledge to confidently and competently restore implants in your practice.

Covering a combination of lectures, demonstrations and hands-on components, the four indepth modules will take you right through getting started with dental implant restorations to managing more complex cases.

Courses start on 8 May 2015:

- Module one - 8 May

- Module two - 26 June

- Module three - 6 November

- Module four - TBC

\section{HELPING YOU NAVIGATE CHANGES TO THE PENSION SCHEME}

The changes to the pension scheme are complicated, but important to understand. Enlisting the expertise of money4 dentists' Independent Financial Advisors (IFAs) provides clarity and understanding on how best to manage your pension.

With over half a century of experience, alongside dependable and specialist fiscal knowledge of the dental industry, money4dentists ensures that no stone is left unturned when examining and strategising your financial needs.

Whether you are considering the best options for your pension, planning for your retirement or organising a mortgage, money4dentists' IFAs are fully equipped to offer comprehensive and bespoke advice.

Pension schemes do not have to be a fiscal minefield, nor do other financial circumstances need to cause worry. Contact money4dentists today to ensure specialised advice and guidance.

For more information please call 0845345 5060, email info@ money4dentists.com or visit www.money4dentists.com.

Further courses start on 20 November 2015:

- Module one - 20 November

- Modules two, three andfour - TBC

Don't miss this opportunity to enhance your knowledge and develop the skills needed to offer your patients first-class restorations. For more information about Ten Dental and The Implant Restoration Course visit the website www.implant-restoration.com or Facebook page Implant Restoration Course-IRC. Alternatively, email courses@tendental.com or call 020 76227610. 